\begin{tabular}{c} 
TẠP CHÍ KHOA HỌC ĐẠI HỌC TÂN TRÀO \\
ISSN: 2354 - 1431 \\
\hline
\end{tabular}

\title{
Bồi dưỡng năng lụ̣c dạy học môn khoa học tự nhiên cho giáo viên trường trung học co'sở
}

\author{
Hoàng Thị Chiên ${ }^{* a}$ \\ ${ }^{a}$ Khoa Hóa hoc Trưòng ĐHSP Thái Nguyên \\ *Email: hoangchiendhtn@gmail.com
}

\section{Thông tin bài viết}

Ngày nhận bài:

$22 / 03 / 2018$

Ngày duyệt đăng:

$12 / 6 / 2018$

\section{Tù khoá:}

Bồi duõ̃ng giáo viên, môn khoa họ tụ nhiên, phát triển năng lực, khám phá thiên nhiên, bảo vệ môi trừ̀ng.

\section{Tóm tắt}

Lĩnh vực giáo dục Khoa học Tự nhiên (KHTN) có ưu thế hình thành và phát triển cho học sinh các phẩm chất như tự tin, trung thực; các năng lực tìm hiểu và khám phá thế giới tự nhiên qua quan sát và thực nghiệm; năng lực vận dụng tổng hợp kiến thức khoa học để giải quyết vấn đề trong cuộc sống, ứng xử với tự nhiên phù hợp với yêu cầu phát triển bền vững xã hội và môi trường. Bài viết sau đây đề cập đến việc bồi dưỡng cho giáo viên năng lực tìm hiểu thế giới tự nhiên thông qua cách tổ chức các hoạt động khám phá và bảo vệ môi trường, nhằm đáp ứng được những yêu cầu của dạy học môn KHTN trong chương trình trường trung học cơ sở (THCS).

\section{I. Đặt vấn đề}

Khoa học tự nhiên là lĩnh vực nghiên cứu về thể giới tự nhiên, nghiên cứu các quy luật vận động và phát triển chung nhất của giới tự nhiên. Kiến thức của lĩnh vực KHTN có thể đến từ các phân môn khác nhau như Sinh học, Vật lý, Hóa học, Khoa học Trái Đất và không gian, thiết kế theo các chủ đề, thể hiện các nguyên lý vận động, phát triển chung của giới tự nhiên. Các nguyên lý đó bao gồm: (1) Sự đa dạng, (2) Mô hình và hệ thống, (3) Năng lượng, (4) Tương tác. Các chủ đề này bao gồm nội dung cốt lõi các khái niệm trong cả khoa học và đời sống và tự nhiên, cung cấp một sự hiểu biết rộng rãi về môi trường, giúp xây dựng một nền tảng mà dựa vào đó học sinh (HS) có thể nghiên cứu sâu thêm ở các cấp học cao hơn. Phát triển năng lực dạy học KHTN của giáo viên $(\mathrm{GV})$ là một trong những vấn đề cấp thiết để thực hiện tốt chương trình giáo dục (GD) phổ thông mới.

\section{Nội dung nghiên cứu}

Mục tiêu của lĩnh vực GD KHTN nhằm hướng đến sự hiểu biết toàn diện về sự vận hành của Trái Đất, về tác động của con người lên Trái Đất và những hành động con người có thể làm để bảo vệ hành tinh sống này. Để đạt được các mục tiêu này, việc dạy học KHTN đòi hỏi người $\mathrm{GV}$ phải có những hiểu biết sâu sắc các kiến thức của lĩnh vực, có năng lực dạy học khoa học theo quan điểm dạy học tích hợp, liên môn, đa ngành trong phạm vi các chủ đề khoa học tự nhiên. Do đó, nội dung bồi dưỡng năng lực dạy học môn khoa học Tự nhiên cho giáo viên ở trường THCS cần hướng tới các nội dung sau:

\section{Bồi dưỡng năng lực thiết kế mục tiêu dạy học khoa học tự nhiên}

Dạy học lĩnh vực KHTN được triển khai theo định hướng phát triển năng lực, theo đó mục tiêu bài học định hướng vào việc mô tả kết quả học tập mong đợi (các khả năng, năng lực học sinh sẽ phải đạt được), chứ không phải là nội dung kiến thức được giáo viên truyền thụ. Các khả năng/năng lực mong muốn hình thành ở người học được xác định một cách rõ ràng, có thể quan sát, đánh giá được.

1.1. Mục tiêu về kiến thức và kĩ năng của lĩnh vục KHTN là hình thành và phát triển năng lục khoa hoc (scientihc literacy) 
Đối với cấp THCS, năng lực khoa học có thể gồm ba hợp phần:

- Xác định vấn đề khoa học

- Giải thích hiện tượng một cách khoa học

- Sử dụng bằng chứng khoa học

Các chỉ số hành vi của năng lực được mô tả qua các biểu hiện của năng lực tìm hiểu tự nhiên $[2$, trang 47- 49], đó là:

- Hiểu biết kiến thức khoa học:

- Tìm tòi và khám phá thế giới tự nhiên

- Vận dụng kiến thức vào thực tiễn, ứng xử với tự nhiên phù hợp với yêu cầu phát triển bền vững và bảo vệ môi trường.

1.2. Mục tiêu về thái độ của lĩnh vục giáo dục này là hình thành phẩm chất: Có trách nhiệm với môi truờng [2, trang 16]

- Sống hòa hợp, thân thiện với thiên nhiên.

- Có ý thức tìm hiểu và sẵn sàng tham gia các hoạt động tuyên truyền, chăm sóc, bảo vệ thiên nhiên; phản đối những hành vi xâm hại thiên nhiên.

- Có ý thức tìm hiểu và sẵn sàng tham gia các hoạt động tuyên truyền về biến đổi khí hậu và ứng phó với biến đổi khí hậu.

\section{Bồi dưỡng năng lực thiết kế nội dung dạy học}

Chương trình tổng thể đã xác định định hướng nội dung chương trình môn KHTN: Ở THCS, nội dung giáo dục KHTN tích hợp các kiến thức, kỹ năng về Vật lý, Hóa học và Sinh học. Các kiến thức, kỹ năng này được tổ chức theo các mạch nội dung (vật chất, sự sống, năng lượng, Trái Đất và bầu trời), thể hiện các nguyên lý, quy luật chung của thế giới tự nhiên (tính cấu trúc, sự đa dạng, sự tương tác, tính hệ thống, quy luật vận động và biến đổi), đồng thời từng bước phản ánh vai trò của KHTN đối với sự phát triển xã hội và sự vận dụng kiến thức KHTN trong sử dụng và khai thác tài nguyên thiên nhiên một cách bền vững. Để thực hiện các nội dung này, cấu trúc nội dung môn KHTN gồm các chủ đề phân môn (Vật lý, Hóa học, Sinh học) và các chủ đề liên môn, nhằm hình thành nhận thức về các nguyên lý, quy luật chung của thế giới tự nhiên, vai trò của khoa học tự nhiên đối với sự phát triển của xã hội và bước đầu vận dụng được kiến thức KHTN trong sử dụng và khai thác tài nguyên thiên nhiên một cách bền vững [2, trang 19].

Theo đó, nội dung môn KHTN sẽ được thiết kế theo các chủ đề, phản ánh quy luật chung nhất của giới tự nhiên. Kiến thức ở mỗi phân môn khoa học được sử dụng làm nguyên liệu/ví dụ thể hiện cho các nguyên lý chung đó. Bên cạnh đó, các chủ đề liên môn được xây dụng dựa trên tiếp cận logic cuộc sống, nội dung được lựa chọn cần phải liên quan mật thiết và có ý nghĩa đối với đời sống con người. Vì vậy, GV cần có năng lực thiết lập mối liên hệ giữa các lĩnh vực kiến thức như sau:

\subsection{Về nội dung về các nguyên lý chung của giới tư nhiên \\ a. Về sụ đa dạng:}

Nhận thức được thể giới bao gồm các sinh vật sống và các yếu tố phi sinh vật. Sự đa dạng trong thể giới tự nhiên và nhân tạo giúp duy trì sự cân bằng trong các hệ sinh thái và cung cấp cho con người những tài nguyên hữu ích.

\section{b. Vè tính cấu trúc:}

Nhận thức được trong học tập khoa học thường sử dụng các mô hình vật lý, mô hình các khái niệm và các mô hình toán học. Đó là những đại diện đã được đơn giản hóa cho các hiện tượng, được xây dựng để tạo điều kiện cho việc hiểu biết các quá trình và các cấu trúc không thể được quan sát trực tiếp, hoặc để đưa ra dự đoán một cách hợp lý và dễ dàng hơn.

\section{c. Về tính hệ thống:}

Hiểu được hệ thống là một tổng thể bao gồm các bộ phận kết hợp với nhau để thực hiện một chức năng. Có các hệ thống trong tự nhiên như hệ tiêu hóa, hệ sinh sản...; cũng có những hệ thống nhân tạo như mạch điện. Các bộ phận của một hệ thống ảnh hưởng đến nhau.

\section{d. Về sư tuoong tác:}

Cần nhận thức được rằng nghiên cứu về sự tương tác giữa và trong các hệ thống giúp con người hiểu rõ hơn về môi trường và vài trò của con người trong đó, nhận biết được có sự tương tác giữa các sinh vật sống và môi trường ở các cấp độ khác nhau: tương tác xảy ra trong cơ thể sinh vật, giữa sinh vật với sinh vật và giữa các sinh vật và môi trường. Tương tác giữa các lực và các đối tượng, giữa vật chất và năng lượng. Các tương tác này thường đi kèm sự chuyến hóa vật chất và năng lượng. Sự tương tác của con ngưòi với môi trường của mình dẫn tới sự phát triến của Khoa học và Công nghệ. Đồng thời, Khoa học và Công nghệ ảnh hưởng đến cách mà con người tương tác với môi trường của mình.

2.2. GV cần thiết lập được mối quan hệ giữa các kiến thức thuộc phạm vi một số linh vục cơ bản
a. Khí quyển và vũ trụ: 
Mô tả và đo được các yếu tố khí hậu đơn giản trong môi trường địa phương, qua đó đánh giá được vai trò của các yếu tố này trong quá trình sản xuất lương thực, hiểu được vai trò của khí quyển đối với sự sống của các loài động, thực vật, đồng thời có khả năng xác định được các khu sinh học chính tại địa phương và trên thế giới.

\section{b. Các dạng đất, thổ nhuỡng và khoáng vật:}

Biết được rằng đất luôn vận động, hiểu được:

- Đất được hình thành như thế nào?

- Đất chứa các sinh vật và giúp cây phát triển

- Đất bị xói mòn và bạc màu...

Hiểu được mối quan hệ giữa đất và các sinh vật, thấy được rằng nguồn tài nguyên khoáng vật trên Trái Đất là hữu hạn.

\section{c. Thực vật và động vật:}

Biết và có khả năng xác định được vô số các loài động, thực vật trong môi trường sống của mình, cảm nhận được ý nghĩa của mạng lưới sự sống và chuỗi thức ăn, hiểu được sự tương tác không ngừng giữa đất, khí quyển, thực vật (tác nhân sản xuất), động vật và con người (tác nhân tiêu thụ). Đồng thời cũng nhận thức được sự suy giảm các loài sinh vật nguy cấp ở mức độ địa phương và toàn cầu, các mối đe dọa đối với chúng và các biện pháp bảo tồn.

\section{d. Năng lượng:}

Nhận biết được sự tồn tại của năng lượng dưới các dạng khác nhau và khả năng kiểm soát năng lượng của con người, hiểu được các chu trình năng lượng và năng lượng bắt nguồn từ mặt trời, hiểu biết về nguồn gốc hình thành nhiên liệu hóa thạch và tác động con người gây ra do sử dụng loại nhiên liệu này.

\section{e. Nưóc:}

Hiểu rằng nước là yếu tố không thể thiếu đối với sự sống, tài nguyên nước có vai trò đặc biệt quan trọng đối với con người, hiểu rõ về chu trình của nước trong tự nhiên, nhận thức được vấn đề ô nhiễm nước cũng như sự có hạn của tài nguyên nước.

\section{g. Con người:}

Hiểu biết về văn hóa và ý nghĩa của văn hóa trong đời sống con người, biết rõ được con người đã sống và sử dụng các tài nguyên của các môi trường khác nhau, thấy việc sử dụng tài nguyên bền vững trong các nền văn hóa khác nhau, nhận thức được sự gia tăng dân số và sự tác động của nó đối với nguồn tài nguyên trên Trái Đất, hiểu được phương thức con người sử dụng và tác động đến môi trường trong đời sống hàng ngày.

\section{Năng lực thiết kế hoạt động trong dạy học} KHTN

\subsection{Theo định hướng chung}

Dạy học KHTN cần áp dụng các phương pháp tích cực hoá hoạt động của người học, trong đó giáo viên đóng vai trò tổ chức, hướng dẫn hoạt động cho học sinh, tạo môi trường học tập thân thiện và những tình huống có vấn đề để khuyến khích học sinh tích cực tham gia vào các hoạt động học tập, tự phát hiện năng lực, nguyện vọng của bản thân, rèn luyện thói quen và khả năng tự học, phát huy tiềm năng và những kiến thức, kỹ năng đã tích lũy được để phát triển [2].

Các hoạt động học tập KHTN của học sinh bao gồm hoạt động khám phá vấn đề, hoạt động luyện tập và hoạt động thực hành - ứng dụng những điều đã học để phát hiện và giải quyết những vấn đề có thực trong đời sống. Các hoạt động học tập có thể được tổ chức trong và ngoài khuôn viên nhà trường thông qua một số hình thức như: học lý thuyết; thực hiện thí nghiệm, trò chơi, đóng vai, dự án nghiên cứu... Tùy theo mục tiêu và tính chất của hoạt động, học sinh cần được tổ chức làm việc độc lập, làm việc theo nhóm hoặc làm việc chung cả lớp. Tuy nhiên, dù làm việc độc lập, theo nhóm hay theo đơn vị lớp, mỗi học sinh đều phải được tạo điều kiện để tự mình thực hiện nhiệm vụ học tập và trải nghiệm thực tế [2].

Giáo viên cần thiết kế hoạt động dạy học khoa học tự nhiên theo chủ đề. Bản kế hoạch dạy học (thiết kế bài học) sẽ thể hiện một cách cơ bản năng lực dạy học KHTN của giáo viên.

\subsection{Ví du minh họa}

Kế hoạch dạy học chủ đề: Hoạt động của hệ sinh thái (theo [3])

Mục tiêu: Giúp học sinh biết được những lợi ích khác nhau mà hệ sinh thái mang lại cho đất đai, động vật và con người thông qua một số thí nghiệm $(\mathrm{TN})$.

Kiến thức: Tích hợp các lĩnh vực: khí quyển và vũ trụ, đất, thổ nhưỡng và khoáng vật, thực vật và động vật, nước.

Nội dung của hoạt động: Hoạt động thực hành và trải nghiệm của học sinh (2 tiết/2 ngày).

Chuẩn bị:

- Các tờ rời để phát cho mỗi học sinh, mỗi nhóm, các nguyên liệu cần thiét cho mỗi nhóm theo nội dung thí nghiệm.

- Chuẩn bị địa điểm: 1 phòng học rộng, 1 khu vực ngoài trời để các nhóm HS tiến hành thí nghiệm trong ngày thứ nhất, thảo luận trong ngày thứ hai.

Tiến hành: 


\section{Ngày 1: Làm thí nghiệm}

1) Bắt đầu hoạt động: GV thông báo cho HS biết rằng các hệ sinh thái xung quanh chúng ta luôn vận động không ngừng, mang lại cho con người những lợi ích thiết thực. Trong hoạt động này, các em sẽ tận mắt thấy được sự vận động hữu ích đó của các hệ sinh thái. Chia lớp thành 4 nhóm HS, mỗi nhóm làm $1 \mathrm{TN}$ tại một khu vực khác nhau. Tất cả các thành viên trong nhóm không được thảo luận với thành viên nhóm khác về thí nghiệm của nhóm mình.

2) Yêu cầu các nhóm đọc kĩ bản mô tả thí nghiệm để tiến hành thí nghiệm, yêu cầu trình bày tóm tắt về cách tiến hành và báo cáo kết quả thí nghiệm của nhóm vào ngày hôm sau, yêu cầu về thảo luận và tìm câu trả lời cho mục Chuyện gì sẽ xảy ra? trong bản mô tả thí nghiệm.

Ngày 2: Trình bày kết quả thí nghiệm và kết nối thông tin

1) Phát tờ rời Hoạt động của hệ sinh thái cho mỗi học sinh. Yêu cầu các nhóm lần lượt giải thích về thí nghiệm của nhóm mình: quá trình làm thí nghiệm, trình diễn thí nghiệm, thảo luận về kết quả thí nghiệm, cung cấp thông tin nhằm trả lời cho các câu hỏi trong mục Chuyện gì sẽ xảy ra? trong bản Mô tả thí nghiệm của mình.

2) Sau khi mỗi nhóm báo cáo xong, từng HS dựa vào tờ rời Hoạt động của hệ sinh thái để tìm xem thí nghiệm của nhóm ứng với hoạt động nào của hệ sinh thái. Khi học sinh lựa chọn xong, đề nghị các em so sánh kết quả với đáp án.

3) Thảo luận với HS: Hệ sinh thái đã giúp ích cho con người như thế nào? HS sẽ làm gì để bảo vệ các hệ sinh thái?

\section{Các tờ rời:}

\section{Tờ rời 1: Mô tả thí nghiệm 1: Nước bẩn - Nước sạch}

Nguyên liệu: Chai nhựa (chai đựng nước khoáng) cắt làm dõi, bông hoặc giấy vệ sinh, than hoạt tính, than củi (có thể thay bằng sỏi sạch), cát, đất, nước và cốc.

Thục hiện: Lật úp phần trên của chai nhựa, bó vào đó một lớp bông dây hoặc giấy vệ sinh. Sau đó, đặt lên trên lớp bông này một lớp than hoạt tính hoặc sỏi rồi đổ lên trên cùng một lớp cát. Nén chặt và đặt nửa trên cùa chai nhựa cắm xuống nửa dưới. Bỏ đất vào cốc nhựa đã có nước đầy $1 / 2$ cốc rồi khuấy đều cho đến khi được một dung dịch nước có màu dất. Sau đó, đổ từ từ cốc nước này vào nửa trên của chai nhựa.

Chuyện gì sẽ xảy ra? Mô tả đặc điểm của nước khi đã được lọc (nước thu được ở nửa dưới chai nhựa). Quan sát các lớp vật liệu lọc và cho biết đất đã bị giữ lại nhiều nhất ở lớp nào? Những hạt đất có kích thước lớn được giữ lại ở lớp nào? (lớp than hoặc sỏi). Những hạt đất có kích thước nhỏ được giữ lại ở lớp nào? (lớp cát). Tại sao lại có hiện tượng đó? Thảo luận: Tại sao nước ao thì đục nhưng nước giếng lại trong? Có nên sử dụng nước ao trong đời sống hàng ngày (nấu ăn, uống...) hay không? Làm thế nào để giữ ao hồ trong sạch?

Tờ rời 2: Mô tả thí nghiệm 2: Nước di chuyển trong cây

Nguyên liệu: Thân cây cần tây còn nguyên lá đã cắt bỏ rễ, dọc mùng, khoai nước, bèo tây, hoa huệ, thược được, cúc... 3-5 ống nghiệm, thuốc nhuộm thực phẩm nhiều màu khác nhau (có thể thay bằng mực), nước, dao tỉa và kính lúp.

Thưc hiện: Đổ nước vào các ống nghiệm đã chuẩn bị và hoà mỗi ống nhiệm một loại màu thuốc nhuộm thực phẩm khác nhau. Màu của thuốc nhuộm trong thí nghiệm này được coi là chất ô nhiễm độc hại trong nước tự nhiên (ví dụ như thuốc trừ sâu, dầu, kim loại nặng như thủy ngân, chì, ...). Cắt bỏ một đoạn ngắn ở phần dưới thân các loại thực vật đã chuẩn bị và cắm vào những ống nghiệm đã pha màu. Để nguyên như vậy đến ngày hôm sau. Các loài thực vật trong thí nghiệm tượng trưng cho các loài thực vật nước hoặc thực vật trong vùng đầm lầy như bèo tây, lau, lách, cỏ; còn nước đã pha màu tượng trưng cho nước ô nhiễm trong khu vực. Ngày hôm sau, cắt thân các loài thực vật thí nghiệm thành những đoạn dài khoảng 2-3 cm để cả nhóm cùng quan sát. Có thể dùng kính lúp để quan sát rõ hơn.

Chuyện gì sẽ xảy ra? Mô tả những gì bạn nhìn thấy. Bạn nhìn thấy nước màu ở những phần nào trên thân các loài cây thí nghiệm? Điều gì đã xảy ra với lá hoặc các cánh hoa? (Khi cắt thân cây thí nghiệm, bạn sẽ nhìn thấy những vạch màu. Đó chính là các mao dẫn giúp vận chuyển nước và chất khoáng đến các phần của cây. Bạn sẽ thấy mép lá và mép các cánh hoa có màu của thuốc nhuộm. Nếu dùng kính lúp quan sát, bạn sẽ thấy gân lá và gân cánh hoa cũng phớt màu thuốc nhuộm). Chuyện gì sẽ xẩy ra nếu người dân bón rau bằng các loại phân bón hoá học hoặc phun thuốc trừ sâu cho rau? Nếu là người làm vườn, học sinh sẽ ứng xử như thế nào? Có dùng phân bón hoá học và thuốc trừ sâu không?

\section{Tờ rời 3: Mô tả thí nghiệm 3: Điều tiết khí hậu}

Nguyên liệu: Hai cành cây có lá, to bằng nhau của cùng một loài cây. Nên chọn những cây có lá to. Hai chai thủy tinh hoặc nhựa trong miệng hẹp, to bằng nhau.

Thưc hiện: Đổ một lượng nước bằng nhau vào hai chai thuý tinh. Cắm một cành cây cồn nguyên lá vào một chai. Ngắt hết lá cùa cành cây còn lại và cắm vào 
chai thứ hai. Bịt kín miệng các chai bằng giấy hoặc nilon. Cần đảm bào rằng mực nước ở hai chai bằng nhau. Đánh dấu mực nước này. Đặt cả hai chai nước đã cắm cành cây ra ngoài nắng hoặc trên bệ cửa số. Để nguyên hai chai qua đêm rồi quan sát.

Chuyện gì sẽ xảy ra? Mực nước ở hai chai thay đổi như thể nào? chai nào mất nhiều nước hơn? Tại sao? (Mục nước trong chai cắm cành có lá thấp hơn do hơi nước bị thoát ra ngoài qua lá. Đó là kết quả của quá trình thoát hơi nước sinh lý ở thực vật).

\section{Tờ rời 4: Mô tả thí nghiệm 4: Sản xuất oxi}

Nguyen liệu: Một cốc thuy tinh, 3 - 5 ống nghiệm thuý tinh loại nhỏ và $3-5$ cầy sống trong nước như rong (hoặc các loài thực vật thả vào bẻ cá cảnh).

Thục hiện: Đổ nước vào đầy cốc thuý tinh. Đặt vào mỗi ống nghiệm 1 cây rong rồi đổ nước vào đầy ống nghiệm. Dùng ngón tay cái bịt kín đầu ống nghiệm và từ từ đặt đầu ống nghiệm vào cốc nước rồi bỏ tay ra sao cho không có bọt khí trong ống nghiệm. Chiếu sáng qua đêm cho cây làm thí nghiệm. Ngày hôm sau quan sát cây rong và các ống nghiệm.

\section{Chuyện gì sẽ xảy ra?}

Có gì khác trong các ống nghiệm? Tại sao? (Ngày hôm sau, bạn sẽ thấy một bong bóng nổi trong mỗi ống nghiệm. Do được chiếu sáng, cây tiến hành quang hợp và giải phóng khí ôxy. Vì ôxy nhẹ hơn nước nên nổi trên mặt nước và bị cốc nước giữ lại, sau một đêm, khí ôxy tập hợp lại và tạo thành bong bóng trong các ống nghiệm). Tại sao nhiều người cùng thở ra khí $\mathrm{CO}_{2}$ mà nồng độ khí $\mathrm{CO}_{2}$ trong không khí vẫn không tăng? chuyện gì sẽ xảy ra nếu không có cây xanh?

\section{Tờ rời 5: Hoạt động của hệ sinh thái}

a. Thực vật hút nước trong đất nhờ bộ rễ và thoát hơi nước ra ngoài qua lá thông qua quá trình thoát hơi nước sinh lý. Đây là quá trình nước bay hơi ra ngoài qua các lỗ nhỏ trên bề mật lá. Cho dù nước vào rễ cây là nước sạch hay nước ô nhiễm, hơi nước thoát ra ngoài hoàn toàn sạch. Lượng hơi nước thoát ra ngoài này hoà với nước bốc hơi từ biển, sông suối...và hình thành mây để tạo ra mưa, một quá trình không thể thiếu trong vòng tuần hoàn nước toàn cầu. Trong các hệ sinh thái, thực vật đóng vai trò quan trọng trong việc quyết định lượng nước giải phóng vào khí quyển và do đó, chúng ảnh hướng đến điều kiện khí hậu của khu vực (TN3).

b. Đất được cấu thành từ các hạt khoáng chất, không khí, nước, vi sinh vật và các chất hữu cơ khảc (do quá trình phân huỷ xác chết động, thực vật). Đất bao gồm nhiều lớp khác nhau. Cần hàng trăm năm mới có thể hình thành nên một lớp đất dầy vài $\mathrm{cm}$. Khi nước ô nhiễm chảy qua các tầng đất, chất lơ lửng bị giữ lại. Chính vì vậy, đất có khả năng lọc và làm sạch nước. Đất còn giúp loại bỏ các chất hoá học độc hại gây ô nhiễm như phân bón, thuốc trừ sâu. Nhiều khoáng chất trong đất có khả năng phản ứng với các chất hoá học độc hại này, tạo thành kết tủa và nằm lại trong đất thay vì thấm vào nước ngầm. Như vậy, đất có thể phá vỡ độc tính của một số chất hoá học, giúp giảm tác động đến các loài sinh vật (TN1).

c. Giống như các loài động vật, thực vật cũng cần thức ăn để sống. Tuy nhiên, cây xanh khác với động vật ở chỗ nó có thể tự tạo ra thức ăn cho mình thông qua quá trình quang hợp. Trong quá trình này, thực vật dùng khí cacbonic $\left(\mathrm{CO}_{2}\right)$, nước và năng lượng mặt trời để tạo ra thức ăn (đường) và khí ôxy. Chính nguồn oxy này giúp duy trì sự sống cho các sinh vật ở cạn. Quá trình quang hợp tạo ra oxy của cây xanh còn giúp giảm ô nhiễm không khí. Những chậu cây xanh đặt trong nhà hay công sở có tác dụng làm cho bầu không khí thêm trong lành (TN4).

d. Trong thân thực vật có những ống nhỏ hay còn gọi là mạch dẫn có tác dụng đưa nước từ rễ cây đi khắp cơ thể. Nếu trong nước có các chất ô nhiễm độc hại, những chất này cũng sẽ được vận chuyển đến các mô của cây và sẽ được tích tụ trong đó. Điều này không có nghĩa là thực vật làm cho các chất độc biến mất mà chúng chỉ làm cho các chất độc thoát ra môi trường một cách từ từ và với một liều lượng nhỏ hơn rất nhiều so với khi các chất độc này ngấm vào nước. Khi các loài thực vật này chết đi, chất độc sẽ lại được giải phóng ra môi trường. Một loài thực vật điển hình cho khả năng lọc chất ô nhiễm là bèo tây. Khi nước ao bị ô nhiễm, hàm lượng chất độc tích tụ trong thân và rễ bèo rất lớn. Người ta đã ứng dụng khả năng này của bèo tây để loại bó chất ô nhiễm trong ao bằng cách thả bèo tây và vớt chúng đem đốt. (TN2)

\section{Kết luận}

Để đạt được mục tiêu môn KHTN ở trường THCS, GV cần được bồi dưỡng để phát triển năng lực dạy học theo các chuyên đề, thiết kế được các kế hoạch bài học/chủ đề đảm bảo các yêu cầu của bài học theo tiếp cận năng lực: Mục tiêu bài học định hướng vào việc mô tả kết quả học tập mong đợi. Vai trò chính của GV là làm thay đổi người học như sẵn sàng tiếp thu các khái niệm mới, tích cực thể hiện, tích cực tương tác, trải nghiệm, nghĩ về cách suy nghĩ... tăng cường hứng thú, sự tự tin, kích thích tư duy sáng tạo của người học, thúc đẩy sự tương tác giữa giáo viên - học sinh và giữa học sinh - học sinh, khuyến khích học sinh trao đổi/tranh luận, 
đánh giá, chia sẻ quan điểm/kinh nghiệm, thúc đẩy/cồ vũ tinh thần hợp tác, kĩ năng làm việc nhóm; Tạo dựng một môi trường học tập thân thiện, học sinh cảm thấy thoải mái (không bị áp đặt, được khuyến khích phát biểu/tự do bày tỏ quan điểm cá nhân, học sinh cảm thấy ý kiến của mình được thừa nhận, được tôn trọng...), hứng thú, tự tin. Nhấn mạnh vào hoạt động tìm hiểu, khám phá, trải nghiệm, đặc biệt là vận dụng kiến thức đề giải quyết các tình huống gắn với thực tế cuộc sống; các hoạt động tự học qua khai thác, tìm kiếm/xử lí thông tin... Kết thúc bài học học sinh cảm thấy mình thay đổi và biết cách thay đổi/sáng tạo lại bản thân... GV sẽ là yếu tố quyết định chất lượng GD trường phổ thông trong mọi lĩnh vực.

\section{TÀI LIỆU THAM KHẢO}

1. Nguyễn Văn Biên (2015), Quy trình xây dụng chủ đề tích hợp về khoa hoc tụ nhiên, Tạp chí Khoa học - Trường ĐHSP Hà Nội;
2. Bộ Giáo dục và Đào tạo (2017), Chuơng trình giáo dục tổng thể, Chuoong trình giáo dục phổ thông, tháng 7/2017;

3. Matarasso, Nguyễn Việt Dũng và Đỗ Thị Thanh Huyền (2003), Khám phá thiên nhiên: Huoóng dẫn thực hiện giáo dục môi truờng với học sinh, Hà Nội, WWF Chuơng trình Đông Dương;

4. Trần Khánh Ngọc và nhóm nghiên cứu (2015), Mục tiêu, chuẩn kết quả, khung nội dung, định huoóng hình thức tổ chức dạy học và đánh giá kết quả học tập trong chuong trình các môn hoc KHTN ở truoòng phổ thông, Báo cáo tổng kết nhiệm vụ Khoa học - Công nghệ cấp Bộ GD\&ĐT mã số B2014 - 17 01NV Trường ĐHSP Hà Nội;

5. Đỗ Hương Trà, Nghiên cưu dạy học tích hợp liên môn: nhũng yêu cầu đặt ra trong việc xây dựng, lựa chọn nội dung và tồ chức dạy học, Tạp chí Khoa học, Đại học Quốc gia Hà Nội (Nghiên cứu giáo dục), sổ 31 (1) 4/2015.

\section{Improving teaching capacity in the subject of natural sciences For secondary school teachers}

\section{Hoang Thi Chien}

\section{Article info}

Recieved:

22/03/2018

Accepted:

$12 / 6 / 2018$

\section{Keywords:}

Teacher training, natural sciences, capacity development, natural exploration, environmental protection.

\begin{abstract}
The field of natural science education has many advantages in establishing and developing students' abilities such as: confidence, honesty; the ability to research and explore the natural world through observation and experimentation; the ability to use scientific knowledge to solve problems in life, capacity to deal with nature in accordance with the requirements of sustainable development of society and the environment. This article examines improving teacher's ability to explore the natural world through the organization of exploration and environmental protection activities that meet the requirements of teaching natural science subjects
\end{abstract}

